\title{
ASSOCIATION BETWEEN SPORTS PRACTICE AND PHYSICAL EDUCATION CLASSES AND LIFESTYLE AMONG ADOLESCENTS
}

original paper

(1) University School of Physical Education in Wroclaw

DOI: https://doi.org/10.5114/hm.2019.83996

\section{TIAGO RODRIGUES DE LIMA, DIEGO AUGUSTO SANTOS SILVA}

Federal University of Santa Catarina, Florianópolis, Brazil

\section{ABSTRACT}

Purpose. Through physical education classes, students receive information regarding the benefits of physical activity for health, in addition to the first effective contact with physical activity, physical exercise, and sports. The aim of this study was to identify the association between sports practice and frequency of physical education classes and aspects related to lifestyle in adolescents.

Methods. The study included 861 students aged 14-19 years from the city of São José, Brazil. Sports practice was assessed with a questionnaire that classified adolescents into 3 groups: does not practise, less than 6 months, and at least 6 months. Independent variables were physical activity, cigarette use, alcohol consumption, sedentary behaviour, number of sleep hours per day, and weekly attendance at physical education classes. Multinomial logistic regression was used to estimate odds ratios (OR) and 95\% confidence intervals (CI).

Results. Higher likelihood of practising sports for at least 6 months was observed in those who performed 2 (OR: 7.54; 95\% CI: 1.20-47.29) and 3 (OR: 8.33; 95\% CI: 2.13-32.55) physical education classes per week. A greater number $(\geq 8)$ of sleep hours per day (OR: 1.45; 95\% CI: 1.31-1.60) and excessive alcohol use (OR: 1.14; 95\% CI: 1.09-1.20) were associated with practising sports for at least 6 months.

Conclusions. Two or more weekly physical education classes were associated with engagement in sports practice outside the school context. Sleeping $\geq 8$ hours per day and excessive alcohol use were directly bound with practising sports for at least 6 months.

Key words: students, exercise, public health, cross-sectional studies, adolescent health

\section{Introduction}

Practising physical activity by children and adolescents is directly related to better bone, metabolic, and mental health, both in the short and long term [1]. However, in 2010, it was estimated that approximately $80 \%$ of the population (11-17 years) were people insufficiently active considering the recommendations of at least 60 minutes of moderate to vigorous physical activity per day [2]. In Brazil, the estimated prevalence of adolescents who did not meet the recommendations regarding physical activity practice in 2015 was $79.7 \%$ [3], indicating that, as globally observed, the prevalence of inactive and insufficiently active adolescents in Brazil is high.
School is known to be a promising environment for health promotion activities [4]. Through physical education classes, students receive information regarding the benefits of physical activity for health, in addition to the first effective contact with the practice of physical activity, physical exercise, and sports [4]. In this sense, physical education classes, apart from playing a fundamental role in motor and human development, are also a key factor in the advance of skills and confidence so that the students can be active throughout their lives [1]. When analysing the relationship between the frequency of physical education classes and health indicators in adolescents, the incorporation of sports practice should be considered, not only because it positively contributes to an increase in the time spent in

Correspondence address: Tiago Rodrigues de Lima, Federal University of Santa Catarina, Sports Center,

Post-Graduation Program in Physical Education, Trindade University Campus, CEP: 88010-970, Florianópolis, Brazil, e-mail: tiagopersonaltrainer@gmail.com

Received: December 18, 2018

Accepted for publication: February 25, 2019

Citation: de Lima TR, Silva DAS. Association between sports practice and physical education classes and lifestyle among adolescents. Hum Mov. 2019;20(3):48-55; doi: https://doi.org/10.5114/hm.2019.83996. 
physical activity [5] and better scores on positive health indicators such as aerobic fitness and muscle strength [1], but also owing to its relevant role in the personality formation of children and adolescents [6].

Sport is considered an integration tool for participants and an important pedagogical instrument in school (or outside the school environment) [7]. In addition to contributing to improvement in the quality of life as a whole (self-esteem, socialization, and health), sport is not limited to the teaching of sports techniques, but reinforces cooperation through education of sensitivity and ethics, as well as collectivism, which are fundamental for the development of personality and social values in children and adolescents [8].

A study carried out with a representative sample of children and adolescents in the city of Londrina, Paraná, Brazil, identified that greater number of physical education classes was directly associated with greater likelihood of practising sports [9]. In addition to the greater number of physical education classes, literature reported that aspects related to lifestyle, such as practice of physical activity [9], greater number of hours of sleep [10], not smoking [11], not consuming excess alcohol [11], and shorter period in sedentary behaviour based on screen time [12], were directly bound to the practice of sports among adolescents.

Considering that participation in physical activities declines considerably with growth, especially from adolescence to adulthood, encouraging the practice of sports among adolescents is important not only owing to its straight health benefits [1], but also because it directly influences the personality of practitioners, and habits acquired in childhood tend to remain in adulthood [2]. In addition, although studies have individually investigated the relationship between sports practice and frequency of physical education classes [9] or aspects related to lifestyle [10,13, 14], such associations were tested in the same analysis model, that is, without considering that physical activity performed during physical education classes can contribute positively to the maintenance of the practice of sports outside the school context, and the benefits attributed to the practice of sports can moderate the association aspects of lifestyle $[10,13,14]$. Thus, investigating the interrelation of these constructs (education-sport-health) can contribute to the diagnosis of benefits of physical education classes for the health of adolescents and provide information for the proposal of better targeted strategies with the objective of reducing the prevalence of inactive or insufficiently active adolescents. Therefore, the aim of this study was to identify the association of sports practice with the frequency of physical education classes and aspects related to lifestyle (practice of physical activity, cigarette use, excessive alcohol consumption, sedentary behaviour based on screen time, and sleep hours) in adolescents from a city in southern Brazil. The hypothesis of this study is that a greater frequency of participation in physical education classes in school, as well as lifestyle-related aspects are directly related to sports practice among adolescents.

\section{Material and methods}

\section{Procedures and participants}

This cross-sectional school-based epidemiological survey was carried out in the city of São José, Southern Brazil. The municipality has the Human Development Index (HDI) of 0.809 and the Gini index of 0.44 [15].

The study population consisted of 5182 students aged 14-19 years enrolled in high schools from the state public network of the city of São José, distributed into 11 eligible schools and 170 high school classes. The sampling process was determined in 2 stages: (1) stratified by state public high schools $(n=11)$; (2) cluster of classes, considering study shift and school grade ( $n=$ 170 classes). In stage 2, all high school students who were present in the classroom on the days of data collection were invited to participate in the study. The probabilistic sample consisted of 1132 students. For the present study, only students with information for all variables were considered, which resulted in a sample of 861 individuals. A posteriori power was calculated on the basis of this number, as well as the prevalence of the distinct exposure variables and outcome, with a design effect of 1.2 and alpha level of $5 \%$. The association between sports practice and sex, age, maternal schooling, economic level, cigarette use, alcohol consumption, sedentary behaviour, number of sleep hours per day, and number of physical education classes showed $>80 \%$ statistical power. Details on the estimates for sample size calculation and the entire sampling process (inclusion, exclusion, eligibility criteria) can be found in literature [16].

Data collection took place in the school environment, in the second half of 2014, during the months from August to November. The work team consisted of undergraduate and graduate students previously familiar with and trained to apply the questionnaire and physical assessments. The questionnaire was applied in the classroom, and data were self-filled by students. 
T. de Lima, D.Silva, Sports practice, physical education classes, and lifestyle

\section{Dependent variable}

The dependent variable was sports practice, investigated through questions [17] regarding the frequency and duration of some of the 4 most common collective sports in schools: soccer, volleyball, handball, and basketball. On the basis of the questions, students were classified into 3 groups: 'does not practise,' 'has been playing sports for less than 6 months,' and 'has been playing sports for at least 6 months'. This classification was adopted because literature reports that the acquisition of new behaviours, such as engagement in sports practice, tends to have greater adherence when maintained for periods longer than 6 months [18].

\section{Independent variables}

The physical activity variable was evaluated by the Brazilian version of the Youth Risk Behavior Surveillance System (YRBSS) questionnaire, translated and validated for Brazil [19]: 'During the last 7 days, on how many days were you physically active for at least 60 minutes per day? (moderate and/or vigorous physical activity)'. This question had answers categorized as insufficiently active ( $0-4$ days) and active ( $\geq 5$ days) [2].

Cigarette use was assessed by the following question from the 'Fantastic Lifestyle' questionnaire, which has validation for the Brazilian population [20]: 'Do you smoke cigarettes?' Individuals who answered 'Never smoked' were considered healthy, and those who responded 'More than 10 per day,' ' 1 to 10 per day,' 'None in the last 6 months,' 'None in the last year' were considered as a risk group, since cigarette use was inversely associated with sports practice among adolescents [11].

The issue of excessive alcohol consumption was evaluated on the basis of questions from the YRBSS questionnaire [19]. The question regarding alcohol use was: 'During the past 30 days, on how many days did you take 5 or more doses of alcohol on the same occasion? (A dose corresponds to a beer can, a glass of wine, a dose of whiskey, cachaça, rum, vodka, etc.)'. Those who answered 'At least once' were considered a risk group, since excessive alcohol consumption is associated with health problems [14].

Sedentary behaviour was investigated by the total time students spent in front of the screen. Time spent on watching television, using the computer, or playing video games was collected with the Brazilian version of the questionnaire on sedentary behaviour based on screen time, validated for Brazilian adolescents [21]. For the definition of the total screen time (television, computer, and video games), the number of hours during the week and weekends was summed up and divided by the 7 days of the week. These variables were later categorized into $<4$ hours per day of screen time and $\geq 4$ hours per day of screen time, since periods above 4 hours per day are associated with a higher risk of cardiovascular diseases [22].

The numbers of sleep hours per day were obtained on the basis of a structured questionnaire, with the question 'What is your bedtime and wake up?' This item was divided in relation to the weekly periods: from Monday to Thursday, Friday to Saturday, Saturday to Sunday, and Sunday to Monday, with answer options regarding bedtime and waking up time. In order to define the average number of sleep hours of students, the average of these results was obtained, in which the number of sleep hours determined from Monday to Thursday was multiplied by 4 , and the values for periods of Friday to Saturday, Saturday to Sunday, and Sunday to Monday were added together and the total was divided by 7 (number of days of the week) [23]. The result was later categorized into $<8$ sleep hours per day and $\geqslant 8$ sleep hours per day, given the direct relationship between short sleep duration ( $<8$ hours per day) and increased number of health risk factors [23].

The variable related to weekly attendance at physical education classes comes from the Santa Catarina Adolescent Behavior questionnaire (COMPAC), whose $r$ value (intra-class correlation coefficient) for independent items and grouped by thematic unit ranged from 0.64 to 0.99 [24]. The number of physical education classes was obtained by the question 'During a typical week, in how many physical education classes do you participate?' The answers to this item were classified into 'No class per week,' '1 class per week,' ' 2 classes per week,' and ' 3 or more classes per week,' since there are corporal practices during these classes, and the sum of the volume of these activities positively contributes to meeting the recommendations regarding the weekly practice of physical activity [25].

\section{Control variables}

Variables used as controls in the analyses were sex (male/female) and age in complete years, later categorized into $14-15,16-17$, and 18-19 years. Maternal schooling was collected in complete years and categorized into $<8$ years of study and $\geqslant 8$ years of study [26]. To define the economic level, the questionnaire proposed by the Brazilian Market Research Association (2011) was used, which allowed to estimate the purchasing power of families. Economic classes are characterized in a decreasing manner according to 
purchasing power on the basis of the accumulation of material goods, housing conditions, number of domestic workers, and the educational level of the family head. In the present study, the economic level was dichotomized into 'high' (A1, A2, B1, B2) and 'low' (C1, C2, D, E). This classification was selected owing to the sampling homogeneity in these 2 categories.

\section{Statistical procedures}

Descriptive and inferential statistics were applied. Fisher's exact test was used to evaluate differences between the dependent variable 'sports practice' and the variable number of physical education classes. Associations between sports practice and independent variables were analysed with multinomial logistic regression, with odds ratio (OR) and 95\% confidence interval (CI) estimation, and the 'no practice' category was considered as reference. In the adjusted analysis of the association between sports practice and the number of physical education classes, gender, age, maternal schooling, and economic level were fixed as controls. In the adjusted analysis between sports practice and other independent variables, all variables were inserted at the same level, regardless of $p$ value in the crude analysis, remaining in the model those with $p \leq$ 0.20 , according to the backward method. Analyses were controlled by all independent variables tested in that model, in addition to the variables of gender, age group, maternal schooling, economic level, and number of physical education classes, inserted as control throughout the analysis. For the evaluation of the final model, a saturated model was estimated, so that the adjustment parameters could be compared with each other. In these comparisons, the multiple determination coefficient $\left(\mathrm{R}^{2}\right)$, the Akaike information criterion, and the Bayesian information criterion were estimated. Interactions between variables significantly associated with sports practice $(p<0.05)$ (physical education classes, alcohol consumption, and the number of sleep hours per day) were tested among themselves; however, no statistical significance was identified for interaction. Statistical significance of the results was accepted at $p<0.05$. The statistical analysis was performed with the Stata 13.0 software (StataCorp, College Station, USA). Sampling weights were used in all analyses, combining clustering within the data structure and design effect.

\section{Ethical approval}

The research related to human use has been complied with all the relevant national regulations and institutional policies, has followed the tenets of the
Declaration of Helsinki, and has been approved by the Ethics Committee for Research with Human Beings of the Federal University of Santa Catarina under CAAE protocol: 33210414.3.0000.0121.

\section{Informed consent}

Informed consent has been obtained from all individuals included in this study or, if aged $<18$ years, from their parents.

\section{Results}

The present study involved 861 students. The majority were female (56.0\%), aged $16-17$ years (59.3\%), and with maternal schooling of up to 8 years (57.1\%). Three out of 10 students came from families classified as low economic level (30.0\%). Approximately 8 out of 10 students were insufficiently active $(77.2 \%)$ and only 2 out of 10 used cigarettes (16.2\%). Moreover, slightly more than $1 / 3$ of the subjects presented excess alcohol consumption (33.7\%) and the majority were characterized by excessive screen time (86.4\%). In addition, $50.7 \%$ of students slept less than 8 hours per day, $67.2 \%$ practised 2 or more physical education classes per week, and $26.6 \%$ had been practising sports for at least 6 months (Table 1).

Table 2 presents values regarding the distribution of students and ORs of the adjusted analysis between sports practice and the number of physical education classes. A higher frequency of students who practised sports was observed among those who performed 2 physical education classes per week. In the adjusted analysis, the higher likelihood of practising sports for at least 6 months was found in those who performed 2 (OR: 7.54; 95\% CI: 1.20-47.29) and 3 (OR: 8.33; 95\% CI: 2.13-32.55) physical education classes per week.

In the adjusted analysis between sports practice and health-related behaviours, higher likelihood of practising sports for at least 6 months was identified in students who consumed alcohol in excess (OR: 1.14; 95\% CI: 1.09-1.20) and those who slept 8 hours or more (OR: 1.45; 95\% CI: 1.31-1.60), regardless of gender, age, maternal schooling, economic level, or weekly attendance at physical education classes (Table 3).

\section{Discussion}

In the present study, it was found that students who performed more physical education classes per week $(\geq 2)$ were more likely to practise sports for at least 6 months. In addition, a greater number of sleep hours per day $(\geq 8)$ and excessive alcohol use were factors directly associated with adolescents who practised sports for at least 6 months. 
T. de Lima, D.Silva, Sports practice, physical education classes, and lifestyle

Table 1. Characteristics of the studied schoolchildren

\begin{tabular}{lc}
\hline Variables & $\begin{array}{c}\text { Sample } \\
n(\%)\end{array}$ \\
\hline Total & $861(100.0)$ \\
\hline Sex & \\
Male & $378(44.0)$ \\
Female & $483(56.0)$ \\
\hline Age (years) & \\
$14-15$ & $270(31.0)$ \\
$16-17$ & $510(59.3)$ \\
$18-19$ & $81(9.7)$ \\
\hline
\end{tabular}

Maternal schooling (years)

$<8 \quad 492(57.1)$

$\geq 8$

369 (42.9)

\begin{tabular}{ll}
\hline Economic level & \\
High & $600(70.0)$ \\
Low & $261(30.0)$ \\
\hline
\end{tabular}

Physical activity

Active

$197(22.8)$

Insufficiently active

$664(77.2)$

Cigarette use

No

$722(83.8)$

Yes

$139(16.2)$

Alcohol consumption

No $571(66.3)$

Yes

$290(33.7)$

Sedentary behaviour (hours per day)

$<4$

$118(13.6)$

$\geq 4$

$743(86.4)$

\begin{tabular}{lc}
\hline $\begin{array}{l}\text { Number of sleep hours per day } \\
<8\end{array}$ & $434(50.7)$ \\
$\geq 8$ & $427(49.3)$ \\
\hline Physical education (classes per week) & \\
0 & $63(7.5)$ \\
1 & $147(17.3)$ \\
2 & $582(67.2)$ \\
$\geq 3$ & $69(8.0)$ \\
\hline Sports practice & \\
Does not practise & $578(67.4)$ \\
Less than 6 months & $53(6.0)$ \\
At least 6 months & $230(26.6)$ \\
\hline
\end{tabular}

As the present study, other research has reported that adolescents who participated in greater number of physical education classes were more likely to practise sports [9]. Among the different contents that guide physical education at school, the teaching and performance of sports practices are among the most impor- tant, given their psychological, cognitive, and healthrelated benefits [13]. In addition, improvements in motor capacity, adoption of healthy living habits, and socialization were aspects related to sports practice in physical education classes [27]. In this sense, it is speculated that the inclusion of sports practices during physical education classes may have contributed to the practice of sports for 6 or more months.

The debate regarding the inclusion of sports in physical education classes is constant. On the one hand, the theoretical opposing trend is supported by the understanding that sports practices cause successful experiences in the minority of students and make most students experience failure [7]. On the other hand, the inclusion of sports in school classes can direct children and young people to pleasurable practices, without avoiding the pedagogical competitions inherent in the learning of motor behaviour deriving from sport [7]. In addition, sports in school can disseminate the democratic discourse that the existence of sport should be based on the possibility of learning for all [7]. However, the application of these aspects in the school context will depend on the adjustment among teachers, students, and the pedagogical project of the educational institution [7]. The present study reinforces this last trend in the sense that some positive aspects of lifestyle were associated with the practice of sports among adolescents.

Among the results identified in this study that are controversial, it was found that students who used alcohol in excess were more likely to practise sports for 6 or more months. The literature on the association between alcohol use and sports practice is not concordant, and a direct and inverse relationship has been identified between these factors [14, 28]. In a study carried out with the participation of 568 students aged 14-20 years in the city of São Carlos, São Paulo, Brazil, alcohol use was associated with less involvement in sports practice [28]. Although a systematic review of longitudinal studies has identified a direct relationship between alcohol use and sports practice in adolescents [14], studies considering change of patterns in relation to sports with alcohol-related alterations are scarce [14], and further research is needed to elucidate the relationship between alcohol and sports practice. It is possible that pressures of academic life such as school and social obligations, coupled with moments of relaxation and fraternization after the practice of sports lead practitioners to consume alcohol as a way to enjoy the moments of rest [29].

In the present study, a greater number of sleep hours per day was directly associated with higher chances 
Table 2. Sample distribution, odds ratios, and 95\% confidence intervals in the adjusted ${ }^{\mathrm{a}}$ association between sports practice and the number of physical education classes in the studied schoolchildren

\begin{tabular}{lcccccc}
\hline \multirow{2}{*}{ Variable } & \multicolumn{2}{c}{ Does not practise $^{\mathrm{b}}$} & \multicolumn{2}{c}{ Less than 6 months of practice } & \multicolumn{2}{c}{ At least 6 months of practice } \\
\cline { 2 - 6 } & \multicolumn{5}{c}{ Adjusted analysis } \\
\cline { 2 - 7 } & $n(\%)$ & $95 \% \mathrm{CI}$ & $n(\%)$ & OR (95\% CI) & $n(\%)$ & OR (95\% CI) \\
\hline \multicolumn{2}{r}{ Physical education (classes per week) } \\
0 & $59(10.40)$ & $3.47-27.09$ & $1(1.93)$ & 1.00 & $3(1.35)$ & 1.00 \\
1 & $120(20.92)$ & $14.59-29.07$ & $5(9.92)$ & $2.41(0.21-27.51)$ & $22(9.84)$ & $3.35(0.35-31.52)$ \\
2 & $358(61.68)$ & $56.48-66.63$ & $41(76.86)$ & $5.74(0.30-28.29)$ & $183(78.94)$ & $7.54(1.20-47.29)$ \\
$\geq 3$ & $41(7.00)$ & $2.23-19.93$ & $6(11.27)$ & $7.36(0.74-50.81)$ & $22(9.84)$ & $8.33(2.13-32.55)$ \\
\hline
\end{tabular}

CI - confidence interval, OR - odds ratio

${ }^{a}$ analysis adjusted for the variables of sex, age, maternal schooling, and economic level

${ }^{\mathrm{b}}$ reference category for the variable of sports practice

Table 3. Odds ratios and 95\% confidence intervals in the adjusted association between sports practice and health-related variables in the studied schoolchildren

\begin{tabular}{|c|c|c|c|c|c|c|c|c|}
\hline \multirow{3}{*}{ Variables } & \multicolumn{2}{|c|}{ Does not practise $^{a}$} & \multicolumn{3}{|c|}{ Less than 6 months of practice } & \multicolumn{3}{|c|}{ At least 6 months of practice } \\
\hline & \multirow[b]{2}{*}{$n(\%)$} & \multirow[b]{2}{*}{$95 \% \mathrm{CI}$} & \multicolumn{6}{|c|}{ Adjusted analysis* } \\
\hline & & & $n(\%)$ & OR & $95 \%$ CI & $n(\%)$ & OR & $95 \% \mathrm{CI}$ \\
\hline \multicolumn{9}{|l|}{ Physical activity } \\
\hline Active & $119(20.7)$ & $18.6-22.9$ & $12(23.1)$ & 1.00 & & $66(27.8)$ & 1.00 & \\
\hline Insufficiently active & 459 (79.3) & $77.0-81.4$ & $41(76.9)$ & 0.97 & $0.61-1.55$ & $164(72.2)$ & 0.77 & $0.19-3.00$ \\
\hline \multicolumn{9}{|l|}{ Cigarette use } \\
\hline No & $480(83.1)$ & $73.8-89.5$ & $42(78.9)$ & 1.00 & & $200(86.9)$ & 1.00 & \\
\hline Yes & $98(16.9)$ & $10.4-26.2$ & $11(21.1)$ & 1.30 & $0.32-5.24$ & $30(13.1)$ & 0.70 & $0.40-12.31$ \\
\hline \multicolumn{9}{|l|}{ Alcohol consumption } \\
\hline No & $387(67.0)$ & $61.6-72.0$ & $34(63.9)$ & 1.00 & & $150(65.2)$ & 1.00 & \\
\hline Yes & $191(33.0)$ & $28.0-38.4$ & $19(36.1)$ & 1.21 & $0.37-3.95$ & $80(34.8)$ & 1.14 & $1.09-1.20$ \\
\hline \multicolumn{9}{|c|}{ Sedentary behaviour (hours per day) } \\
\hline$<4$ & $89(15.1)$ & $6.5-31.3$ & $8(15.8)$ & 1.00 & & $21(9.1)$ & 1.00 & \\
\hline$\geq 4$ & $489(84.9)$ & $68.7-93.5$ & $45(84.2)$ & 0.73 & $0.17-3.05$ & $209(90.9)$ & 1.16 & $0.59-2.27$ \\
\hline \multicolumn{9}{|c|}{ Number of sleep hours per day } \\
\hline$<8$ & $302(52.5)$ & $49.0-56.0$ & $27(50.7)$ & 1.00 & & $105(46.0)$ & 1.00 & \\
\hline$\geq 8$ & $276(47.5)$ & $43.9-51.0$ & $26(49.3)$ & 1.13 & $0.63-2.01$ & $125(54.0)$ & 1.45 & $1.31-1.60$ \\
\hline
\end{tabular}

CI - confidence interval, OR - odds ratio

${ }^{\text {a }}$ reference category for the variable of sports practice

* The variables of sex, age, maternal schooling, economic level, and physical education classes were inserted as control throughout the analysis regardless of $p$ value. In addition, health-related variables were inserted as possible effect modifiers, where those with $p \geqslant 0.20$ were withdrawn. The final model formed by the variables of alcohol consumption and number of sleep hours per day (besides variables fixed as control) presented pseudo value $\mathrm{R}^{2}=0.0950$; Akaike information criterion $(\mathrm{AIC})=1265.93$ and Bayesian information criterion $(\mathrm{BIC})=1342.06$. Compared with the saturated model (pseudo $\mathrm{R}^{2}=0.0996$; $\mathrm{AIC}=1271.55 ; \mathrm{BIC}=1376.23)$ and the null model (pseudo $\left.\mathrm{R}^{2}=0 ; \mathrm{AIC}=1367.40 ; \mathrm{BIC}=1376.92\right)$, the final model had a value of 0.38 and $<0.001$, respectively, by the likelihood ratio test. 
T. de Lima, D.Silva, Sports practice, physical education classes, and lifestyle

of practising sports for at least 6 months. These findings are in agreement with observations described in literature $[10,30]$. Although there are no formal guidelines for classifying the number of sleep hours sufficient for schoolchildren, the National Sleep Foundation classifies periods shorter than 8 hours per day as insufficient for children and adolescents [23]. In this sense, even if all the functions attributed to sleep are not elucidated, complete sleep rest is one of the main strategies for the restoration of physical and mental abilities, possibly justifying the direct relationship between a greater number of sleep hours and practising sports for at least 6 months [30].

Considering the direct relationship between a greater number of physical education classes and sports practice, and the health benefits derived from this practice, the physical education professional can provide conditions for students to obtain autonomy in relation to sports practice, which would imply the maintenance of these practices after the formal school period. Moreover, the role of the physical education professional not only as an integrator of the different constructs such as education, sports, or health, but also as the one responsible for the formation of healthy environments and habits should be highlighted, since such actions are important contributions to the improvement of schoolchildren's quality of life [8]. Thus, although physical education in school is guaranteed by the Brazilian law, specifications regarding the duration or number of sessions are not established, and policies should be proposed with the objective of determining the minimum achievement of 2 physical education classes per week.

Some limitations of the present study should be enumerated. Among them, there is the collection of information through a self-administered questionnaire, with a risk of response bias for the identification of variables related to lifestyle, although the questionnaire had been validated for the investigated population. Another limitation of the study concerns the question regarding the activity performance domain, which does not allow identifying the context in which a sports modality was performed. In addition, investigating only 4 sports modalities is another limitation, since it is possible that information regarding other sports has not been evaluated. Moreover, the cross-sectional design of the study, which does not allow inferring cause and effect relationships in the associations between sports practice and independent variables, is considered a study limitation. Although the study evaluated a representative sample of schoolchildren and the associations of interest showed sufficient statistical power, which reduces the likelihood that they occurred at random, the research was developed in schools of the state public education network, whose data cannot be assumed relevant for the private school system. However, the identification of aspects related to sports practice, which may contribute to an increase of physical activity volume, is considered a strong point of this study.

\section{Conclusions}

The accomplishment of 2 or more physical education classes per week is directly associated with the engagement in sports practice outside the school context and, consequently, increases the levels of habitual physical activity. Information regarding the importance of maintaining adequate sleep length $(\geq 8$ hours per day) can contribute to the involvement in sports practice. In addition, although the present study identified a direct relationship between alcohol use and sports practice for at least 6 months, further research is needed to identify the necessary conditions for participation in sports practice to have beneficial results in terms of preventing alcohol use in adolescents.

\section{Acknowledgments}

The authors thank all the students who participated in the study.

\section{Disclosure statement}

No author has any financial interest or received any financial benefit from this research.

\section{Conflict of interest}

The authors state no conflict of interest.

\section{References}

1. Poitras VJ, Gray CE, Borghese MM, Carson V, Chaput JP, Janssen I, et al. Systematic review of the relationships between objectively measured physical activity and health indicators in school-aged children and youth. Appl Physiol Nutr Metab. 2016;41(6 Suppl 3): S197-S239; doi: 10.1139/apnm-2015-0663.

2. World Health Organization. Global strategy on diet, physical activity and health. Geneva: World Health Organization; 2004. Available from: https://www.who. int/dietphysicalactivity/strategy/eb11344/strategy_ english_web.pdf.

3. Brazilian Institute of Geography and Statistics. National School Health Survey (PeNSE) 2015 [in Portuguese]. Rio de Janeiro: IBGE; 2015.

4. McKenzie TL, Lounsbery MA. The pill not taken: revisiting physical education teacher effectiveness in a public health context. Res Q Exerc Sport. 2014;85(3):287292; doi: 10.1080/02701367.2014.931203. 
5. Coledam DHC, Ferraiol PF. Engagement in physical education classes and health among young people: does sports practice matter? A cross-sectional study. Sao Paulo Med J. 2017;135(6):548-555; doi: 10.1590/1516-3180. 2017.0111260617.

6. Malina RM. Children and adolescents in the sport culture: the overwhelming majority to the select few. J Exerc Sci Fit. 2009;7(2 Suppl):S1-S10; doi: 10.1016/ S1728-869X(09)60017-4.

7. Sadi RS. Sports, politics and society [in Portuguese]. Brasília: University of Brasilia; 2004.

8. De Lima LRA, Teixeira DM, dos Santos ECM, Petroski EL. Contribution of physical education in the fields of sports, physical activity, health and education for children and young people living with HIV [in Portuguese]. Rev Bras Cineantropom Hum. 2016;18(2):243258; doi: 10.5007/1980-0037.2016v18n2p243.

9. Coledam DH, Ferraiol PF, Pires Junior R, dos-Santos JW, Oliveira ARd. Factors associated with participation in sports and physical education among students from Londrina, Paraná State, Brazil [in Portuguese]. Cad Saude Publica. 2014;30(3):533-545; doi: 10.1590/0102311 X00087413.

10. Fullagar HH, Skorski S, Duffield R, Hammes D, Coutts AJ, Meyer T. Sleep and athletic performance: the effects of sleep loss on exercise performance, and physiological and cognitive responses to exercise. Sports Med. 2015;45(2):161-186; doi: 10.1007/s40279-0140260-0.

11. Takakura M. Relations of participation in organized activities to smoking and drinking among Japanese youth: contextual effects of structural social capital in high school. Int J Public health. 2015;60(6):679-689; doi: 10.1007/s00038-015-0697-4.

12. Da Silva KS, Nahas MV, Peres KG, Lopes AS. Factors associated with physical activity, sedentary behavior, and participation in physical education among high school students in Santa Catarina State, Brazil [in Portuguese]. Cad Saude Publica. 2009;25(10):2187-2200; doi: 10.1590/S0102-311X2009001000010.

13. North Western Counties Physical Education Association. World-wide survey of school physical education: final report. Paris: UNESCO; 2014.

14. Kwan M, Bobko S, Faulkner G, Donnelly P, Cairney J. Sport participation and alcohol and illicit drug use in adolescents and young adults: a systematic review of longitudinal studies. Addict Behav. 2014;39(3):497506; doi: 10.1016/j.addbeh.2013.11.006.

15. United Nations Development Program. Human Development Index, 2013. Available from: http://www.pnud. org.br/IDH/Atlas2013.aspx?indiceAccordion=1\&li $=$ li_Atlas2013.

16. Silva DAS, Tremblay M, Pelegrini A, Dos Santos Silva RJ, de Oliveira ACC, Petroski EL. Association between aerobic fitness and high blood pressure in adolescents in Brazil: evidence for criterion-referenced cut-points. Pediatr Exerc Sci. 2016;28(2):312-320; doi: 10.1123/ pes.2015-0172.
17. Silva DAS. Brazilian guide for the evaluation of physical fitness related to health and habits of life - stage I [in Portuguese]. Brasília: National Council for Scientific and Technological Development; 2013.

18. Prochaska JO, Velicer WF. The transtheoretical model of health behavior change. Am J Health Promot. 1997; 12(1):38-48; doi: 10.4278/0890-1171-12.1.38.

19. Guedes DP, Lopes CC. Validation of the Brazilian version of the 2007 Youth Risk Behavior Survey. Rev Saude Publica. 2010;44(5):840-850; doi: 10.1590/S003489102010000500009.

20. Rodriguez Añez CR, Reis RS, Petroski EL. Brazilian version of a lifestyle questionnaire: translation and validation for young adults. Arq Bras Cardiol. 2008;91(2): 92-98; doi: 10.1590/S0066-782X2008001400006.

21. Silva DAS, Gunnell KE, Tremblay MS. Factor structure of responses to the Portuguese version of questions about screen time-based sedentary behavior among adolescents. J Phys Act Health. 2018;15(4):263-268; doi: 10.1123/jpah.2016-0382.

22. Wijndaele K, Brage S, Besson H, Khaw KT, Sharp SJ, Luben $\mathrm{R}$, et al. Television viewing time independently predicts all-cause and cardiovascular mortality: the EPIC Norfolk study. Int J Epidemiol. 2011;40(1):150159; doi: 10.1093/ije/dyq105.

23. Eaton DK, McKnight-Eily LR, Lowry R, Perry GS, Presley-Cantrell L, Croft JB. Prevalence of insufficient, borderline, and optimal hours of sleep among high school students - United States, 2007. J Adolesc Health. 2010; 46(4):399-401; doi:10.1016/j.jadohealth.2009.10.011.

24. Silva KS, Nahas MV, Hoefelmann LP, Lopes AS, Oliveira ES. Associations between physical activity, body mass index and sedentary behaviors in adolescents [in Portuguese]. Rev Bras Epidemiol. 2008;11(1):159_ 168; doi: 10.1590/S1415-790X2008000100015.

25. World Health Organization. Global recommendations on physical activity for health. Geneva: World Health Organization; 2010.

26. Brazilian education: indicators and challenges [in Portuguese]. Brasília: National Education Forum; 2013.

27. Tassitano RM, Barros MV, Tenório MC, Bezerra J, Florindo AA, Reis RS. Enrollment in physical education is associated with health-related behavior among high school students. J Sch Health. 2010;80(3):126133; doi: 10.1111/j.1746-1561.2009.00476.x.

28. Pratta EMM, Santos MA.Risk factors for alcohol use in the life and in the year among high school teenagers [in Portuguese]. SMAD Rev Eletrônica Saúde Mental Álcool Drog. 2013;9(1):18-24; doi: 10.11606/issn.18066976.v9i1p18-24.

29. National Health and Medical Research Council. Australian guidelines to reduce health risks from drinking alcohol. Canberra: Commonwealth of Australia; 2009.

30. Venter RE. Role of sleep in performance and recovery of athletes: a review article. S Afr J Res Sport Phys Educ Recreation. 2012;34(1):167-184. 